\title{
CHILD'S ATTACHMENT TO MOTHER AS THE BASIS OF MENTAL DEVELOPMENT TYPOLOGY
}

\author{
Galina V. Burmenskaya \\ Lomonosov Moscow State University \\ Moskow
}

The article shows the role of the attachment system (child-mother interactions) in development of a wide spectrum of individual personality characteristics. Emotional attachment of the child to mother is considered as a complicated system of internal regulation and a basis of typology of mental development. Results of a series of empirical studies show the connection between the type of attachment, formed at the early stages of child development, and characteristics of his/her autonomy, consciousness (self-concept and self-esteem) and empathy in preschool and middle childhood.

Keywords: attachment, typology of mental development, autonomy, self-concept, self-esteem, empathy, preschool and middle childhood.

It is universally recognized in modern psychology that the family, being by definition a multiple complex of close, long-term and emotionally rich interpersonal relations, bears in itself the fundamental conditions of mental development and formation of the personality as a whole. The child becomes involved in these relations from the moment of his birth (and even earlier: during the prenatal period). With the use of such an approach many classical problems of psychology concerning laws of cognitive and emotional development have been transferred to the context of analysis of the child's communication and activity within the limits of parent-child relations: mother-child, father-child, sibling-child, grandparent-child and so on. Year after year new proofs of versatile and constant influence of early emotional ties on the formation of one's personal characteristics have been revealed. Extensive research on child's attachment to mother illustrates fruitfulness of such a paradigm. 


\section{Problem of Typology}

\section{of Age-Related Development}

It is noteworthy that studying the phenomenon of attachment made it possible to connect naturally two major, though unfortunately separate, aspects of the theory of ontogeny. On the one hand, it is an age-genetic aspect that discloses conditions, mechanisms and consecutive stages of development; on the other hand, it is a differential and psychological aspect that describes a wide spectrum of individual variants of development in ontogeny. However, modern developmental psychology lacks sufficient elaboration of the problem concerning the dynamics of individual differences. There still exist the consequences of a long-term period, when individual differences were traditionally studied without taking into consideration their genesis and development, as well as their real age-related dynamics, whereas the age aspect of ontogeny was mostly limited to describing its normative path. At the same time the diversity of various forms and variants of development, in fact, remained outside the field of vision of researchers specializing in developmental psychology. As a result, the ontogeny of many essential aspects of cognitive and emotional / personality spheres has been represented in a generalized, i.e. abstract and unified form, hiding the real diversity of typological and individual variants of development.

In this respect, the realm of research on child's emotional attachment to mother is a happy exception. Using a modern typological approach, it is possible to create in this area a vast and structured picture of the main variants of age-related development. The typology here is a procedure of theoretical analysis aimed at the systematization of various individual features by means of identification of their genetic basis, which is supposed to be the basic age-related new formations (Burmenskaya, 2000; 2002). It became possible owing to the fact that J. Bowlby (Bowlby, 1969; 2003) and M. Ainsworth (Ainsworth, et al., 1978), founders of the theory of attachment, described attachment not only as a basic characteristic formed in mother-infant interaction (in other words, in new formations), but from the very beginning they drew attention of researchers to the fact that attachment is never the same: different children have different qualitative-specific forms (types) of attachment.

\section{Concept of Attachment}

Although the concept of attachment is somewhat different in various conceptions, nevertheless the formation of a close, individually directed, emotional mother-infant tie has been recognized as common in all interpretations. Thus, for example, the concept of attachment in works by M.I. Lisina (Lisina, 1986) appears in description of forming mother-child interaction and is considered as one of major products of communication activity, in particular, in situational/personality form of adult-child interaction. J. Bowlby (Bowlby, 1969; 2003) interpreted attachment mechanisms by using a general theory of systems. A system approach made it possible for him to represent attachment not only as a complex of small child's behavioural and emotional relations being watched from outside, but as a complicated system of internal regulation. This regulatory system in its fundamental principle is focused on the small child's search for protective proximity and contact with his mother. Attachment system of infants and older children becomes active when they feel some danger, anxiety or any discomfort (pain, cold etc). His contact with mother removes anxiety and makes the child feel secure; this sensation cannot be overestimated, since only being free from feeling danger, anxiety or pain, the child is able to switch his attention to the world around him and to solve problems of cognizing and mastering it. J. Bowlby and his followers have shown in their works that attachment is a very complicated system consisting of three types of components:

1. Cognitive components in the form of identification signs, images and ideas, connected with the child's mother (or with another close person replacing her permanently);

2. Emotional reactions addressed to the child's mother and signalling her of his needs and of meeting them;

3. Proper behavioural reactions: crying, smiling, approaching, clinging etc.

Numerous facts indicate the importance of attachment. For example, it is widely known that young children are deeply depressed when separated from their mothers. Painful experience can be caused by lengthy activation of the regulating attachment system when there are no usual stimuli, which stop its action i.e., when contact with 
mother is impossible. In these conditions the small child experiences a state of acute maladjustment and oppression of all other forms of behaviour.

It should be noted that attachment system is strictly individual - it is adjusted to the concrete person and owing to it the child de facto cannot switch over to someone else quickly and without serious consequences. That is why, when separated from mother - even getting the best care from strangers - the child stops being interested in the world around, does not eat and sleep properly, feels anxiety, despair or apathy and often falls ill. It can be stated without any exaggeration that when the child comes into this world, he perceives it literally through the prism of his attachment to mother. According to John Bowlby, the child's orienting / cognitive processes and emotional / personality sphere develop not by themselves but within limits of attachment system - as a means of providing the child's tie to mother and removing his emotional discomfort. Attachment not only makes him feel secure in face of the new and complex world but also expresses his internal need for contacts with people. Within the framework of his attachment to mother the infant creates his first pattern of interpersonal relations which is initially connected with his cognitive, emotional and behavioural spheres.

In process of the child's development and increasing independence his attachment to mother transforms but does not disappear. His need for direct physical contact and proximity replaces a more complex in form and content, though, in fact, same, need for psychological security and support, confidential communication, as well as his mother's flexible but not too strict guidance. The circle of persons to whom the child teenager and then adult feels attachment becomes wider, though as a rule, the role of mother as an attachment figure remains. As demonstrated numerous studies of the recent one-and-a-half or two decades, the influence of mother's attachment is not limited to early stages of childhood but extended over the adult's life (Fraley, 2002; Jacobsen, Edelstein, and Hofmann, 1994; Mikulincer, et al., 2002; Thompson, 1999; 2000). In its turn the sphere of attachment influence appears to be much wider than that of proper child-parent relations covering friendly and romantic relations with peers and partners (Fraley, and Shaver, 2000; Kerns, et al., 1996; 2000).

\section{Attachment as the Basis of Mental Development Typology}

Being obligatory for all normally developing children, attachment acquires a qualitatively different character which depends on quite a number of conditions and first of all on mother's behaviour, i.e., her sensitivity, attitude to the child, emotional acceptance, consistent responsiveness and some other characteristics. It is used to distinguish at least four different types of attachment: a secure type, corresponding to optimum process of the child's development; two insecure ones - ambivalent (or anxious-aggressive) and avoidant (or anxious-inhibited); and a disorganized type that usually accompanies impaired child development. As far back as 1970-80s the first studies showed the great significance of the types of child's attachment to mother. On their basis the system of expectancies regarding other social participants has been established. In fact such a system of expectations acts as a mediator of the child's subsequent interactions with the world around and thus becomes a major mechanism of influence on other aspects of his development; for example, on his ego image. Subsequent studies have revealed even greater impact of attachment on the child's emotional/personality, communicative and even cognitive development as well as on the types of arising problems. We can state now that the type of attachment defines to a large extent the originality of the "trajectory" of child's further development.

In particular, it has been shown that an attachment type retains its importance in adults, at least in two aspects. Firstly, attachment keeps its role as an active mental mechanism in creating interpersonal relations including friendship, love and family relations. For example, there is a tendency of continuity of an attachment type from one family generation to another one, up to the cases of distinctive "intergeneration inheritance", when a certain type of attachment is transferred from grandmother to mother and then to daughter and granddaughter. Secondly, a type of the child's attachment to mother keeps its imprint on the characteristics of emotional and cognitive spheres of young people and even adults. At present there is a sphere of extensive research on the features of personality psycho-dynamics of different attachment types. Analyzing this field it is necessary to emphasize several different, though interconnected, aspects: 
1. Dominant spectrum of emotional displays;

2. Type of emotional self-regulation;

3. Peculiarities of self-actualization and self-attitude;

4. Some cognitive processes (e.g. memory, etc).

For example, a secure type of attachment suggests positively coloured relations, when an attachment figure is perceived as sensitive and accessible and an attachment subject as important and worth of love and care. On this basis such an attitude is formed when close relations provide security and support and make free from anxiety and tension. That is why people with secure attachment are also capable of self-exposure and free expression of feelings to a larger extent than others. They are not inclined to accumulate negative emotions and exaggerate life hardships. Their more positive and friendly attitude to other people helps to display anger in a controllable and not hostile manner. In stress situations they are more capable of retaining self-assertion and believe in support from others; besides, they regard difficulties as temporary and surmountable. Openness and flexibility, willingness to recognize their errors readily, absence of excessive fear of criticism are typical of this kind of people (Mikulincer, et al., 2002).

People whose personality has been formed in conditions of insecure attachment to mother have quite different emotional/personality sphere and different complex of individual and typical features. So, a distinctive trait of children and adults with an avoidant type of attachment is a feeling of discomfort in close relations, a sensation of vulnerability and dependence. As a result, protective mechanisms of emotional hypoactivation are formed. It means not only repression of unpleasant information but reduction of its perception, exhaustion of affective sphere and emotional closure. Tendency to dissociation in interpersonal relations and striving for reliance only on themselves are typical of their behaviour. On the contrary, people with anxious and ambivalent type of attachment display exaggerated need for acceptance, support and confirmation of their significance by partners. This group is characterized by emotional hyperactivation when the sphere of close relations is penetrated with diffidence and anxiety while their memory readily actualizes feelings of offence and anger. In their behaviour dominate exaggerated attention to an attachment figure and striving for minimizing distance and reaching acceptance by all means, i.e., this is a position of dependence and a kind of clinging (Mikulincer, et al., 2002).
On the whole, the results of extensive and diverse research make it possible to suggest that attachment may serve as genetic basis of different typological variants of realization of ontogeny, i.e., various types of attachment create a certain complex of individual and typical characteristics of personality. This suggestion has become the basis of the cycle of empirical research on qualitative features of mental development of children with different types of attachment to mother in preschool and middle childhood. Further, we represent some of these works carried out by postgraduates and students writing a degree thesis at the Chair of Age Psychology of the Moscow State University.

\section{Attachment and Autonomy of Personality \\ in Preschool and Middle Childhood}

The general hypothesis of research (Pupyreva, 2007) consisted in the suggestion that the features of the child's attachment to mother exert influence on the formation of his autonomy as one of the basic lines of development in ontogeny. Autonomy has never been primary in ontogeny - it is always preceded by the stage of joint action with the adult. Therefore, the concept of co-regulating behaviour as a process of coordinating intentions, efforts and actions of the child and mother has been introduced here as a major mediator. School children of the $1^{\text {st }}$, $2^{\text {nd }}, 3^{\text {rd }}$ and $5^{\text {th }}$ forms of Moscow secondary schools and preschoolers (total 126 children of 5.04-11.05 years old) participated in this research experiment. 76 children of the $1^{\text {st }}$ and $3^{\text {rd }}$ forms have been included into the basic sample.

Empirical investigation of features linked to formation of autonomy in primary school pupils has been carried out on the basis of a specially worked out semi-structured questionnaire consisting of eight semantic blocks, which reflected major structural components of autonomy in middle childhood:

1. Independence in studies;

2. Independence in household sphere;

3. Independence in choosing occupation;

4. Freedom in expressing own opinion;

5. Freedom in choosing friends;

6. Preference of independent or joint activity with the adult;

7. General assessment by the child of his own independence; 
8. Mother's attitude to the child's independence (from the child's point of view).

The findings have demonstrated that most primary school pupils.

1. Perceive their mothers as a source of help and support;

2. Have a need for mother's participation in their mastering of various aspects of social life outside home (at school, when communicating with peers, etc);

3. Continue to have a need for mother's presence;

4. Have a need for mother's help with their studies.

Most children from the sample (two-thirds) were those with secure attachment to mother (B), one-third of them were pupils with insecure types of attachment (A and C). The latter category considers their mothers not enough sensitive and supportive, does not feel emotional proximity to them and prefers not to reveal their inner life. Thus, relations between mothers and children with avoidant attachment are often characterized by indifference or even satiety with communication whereas children with ambivalent attachment feel the lack of close relationship with mother. Three groups of children have been formed according to autonomy levels: low (12\%), average (75\%) and high (13\%). It should be noticed that general assessment by children of their own autonomy, i.e., "a feeling of independence" named by us so by analogy with the concept of "a feeling of being the adult", which expressed the sensation of oneself as a subject of actions and relations, was essentially higher than their independence in real activity as well as in concrete aspects of relations with mother. $26 \%$ children of the sample expressed their strong dissatisfaction with the attitude to them as to dependent persons.

Mathematical analysis of the data has shown a significant (though moderate in magnitude) influence of emotional attachment to mother on the level of the child's autonomy, which supports the main hypothesis of the study. In particular, the influence of the attachment type (A, $\mathrm{B}$ and $\mathrm{C}$ ) on the level of autonomy has been confirmed by the results of dispersive analysis of the data $(\mathrm{F}=2.70$ with $\mathrm{p}=0.07)$. We also discovered a connection between a degree of reliability of attachment (insecure, relatively secure and secure) and a level of autonomy (low, average and high): when calculating contingency factor a value of "chi square" criterion was $15.46(\mathrm{p}=0.004)$. Taking into consideration a relatively small size of the sample, this value may be considered as evidence of a close connection between these variables.
At the same time the established connection between a degree of reliability of attachment and a level of the child's autonomy by its qualitative character appeared inversely proportional $(\mathrm{r}=0.25$ with $\mathrm{p}=0.05)$ : the higher the children assessed reliability of their attachment to mother, the lower was their subjective sensation of autonomy and vice versa. Children with insecure types of attachment (A and C) displayed the highest degree of autonomy while children with secure attachment (B) demonstrated the lowest one.

The analysis of these results has shown that the highest independence in children with insecure types of attachment first of all reflects their tendency to keep mother at a distance since interaction with her often entails emotional tension. In this case autonomy appears to be as if untimely and forced. At the same time children with a strong need for joint activity and close emotional and personal communication with mother also belong to the group of children with secure attachment. Their tendency to wider autonomy appears too, though somewhat later - by the time the child becomes a teenager. Besides, differences in the level of the child's autonomy, features in structure of display of independence in primary school pupils with different types of attachment have been also observed. Irrespective of the attachment type all children had high values on scales "General assessment by the child of his independence" and "Mother's attitude to her child's independence", i.e., children's subjective assessment of their independence is much higher than its realization in studying as well as in other concrete fields of activity and mutual relations. Meanwhile all children had the lowest values on scales "Independence in studies" and "Freedom of expression of opinion".

It was stated above that these manifestations of independence characteristic for primary school pupils to a considerable extent are agerelated and specific and in a less degree are stipulated by influence of attachment characteristics: studying is a new and difficult sphere for most children where they feel a lack of self-confidence and dependence on adult's help. And yet children with secure attachment are inferior to their peers with avoidant attachment in freedom of choice of friends $(p=0.004)$, freedom of expression of opinion ( $p=0.01)$ and (on a level of statistic tendency) freedom of choice of occupation ( $\mathrm{p}=0.10)$, as well as freedom of preference of independent activity to mutual actions with adults $(\mathrm{p}=0.03)$. 
Thus, secure attachment creates preconditions for relatively moderate development of autonomy at the expense of keeping close emotional tie to mothers. One of the basic characteristics of secure attachment consists in children's attitude to consent with their mothers that entails voluntary acceptance of regulation and control of many areas of life (coregulation remains). In other words, children with secure attachment keep preference of mutual activity with adults owing to close emotional tie to mothers. The studies have demonstrated that mutual activity of children with secure attachment with their mothers is characterized by emotional involvement and pleasure. It should be emphasized that developed autonomy requires sufficient and successful experience in various life situations and this experience can be obtained by the child only in the course of co-operation and co-regulation of his efforts with a close adult - mostly with mother. Nature of co-regulation process depends on a type of the child's attachment to mother. Coordination of actions between mothers and children with avoidant attachment is more tense and corresponds to the least safe variant of emotional/ personality development. Process of coordination of actions and efforts between mothers and children with secure attachment usually is of voluntary character and proceeds willingly and easily.

Autonomy in middle childhood is marked by complicated dynamics and structure, various components of which are formed not simultaneously. In most cases the general subjective feeling of independence in younger school children leaves behind the development of many concrete displays of independence (at home, when choosing friends and occupation in spare time, etc), creating a kind of "zone of the nearest development" in the formation of autonomy in middle childhood. Children feel the least independent when at school. Though by the end of middle childhood independence in this sphere increases (mostly it concerns children with secure attachment), even for the $3^{\text {rd }}$-graders school studies still remain their weak point, i.e., an area of minimum independence. This disturbing situation once more provides evidence of problems in the field of organization of primary education.

Children with different types of attachment have different features of independence in their relations with mothers. On the whole, children with insecure types of attachment show more autonomy than children with secure attachment. Nevertheless, the main distinction is expressed not in a degree of autonomy, but in its qualitative features: as to secure independence, in fact, it is backed with a feeling of competence and self-confidence, acquired in the course of co-regulation of activity with mother, i.e., as a result of voluntary and flexible coordination of actions and a good emotional contact with mother. In case of insecure attachment a high degree of the child's independence is backed with internal dissociation from mother or tense assertion of his point of view.

Thus, it is possible to see that the investigation of connection between attachment and autonomy, carried out on the basis of combination of typological approach and principles of age-related analysis has made it possible to specify a picture of trajectories of emotional/personality development in ontogeny. The use of new data has allowed to disclose the thesis concerning the fact that the child's attachment to mother fulfils the role of genetic base, various forms (types) of which create a special scope of the child's individual-typical features.

\section{Attachment and Formation of Self-Consciousness}

A number of works of this cycle has been dedicated to the research on contribution of attachment to mother to the formation of the child's self-consciousness (self-concept and self-esteem). Previously it was established that the character of attachment to mother in early and preschool age affected the child's self-perception and self-attitude (Avdeyeva, and Haimovskaya, 2003; Cassidy, 1988). Some studies have been carried out in order to find out to what extent such a connection continues in middle childhood. Children then become much more independent, their subjective significance of communication with peers increases essentially whereas their relationship with parents starts sidelining gradually.

The results of our studies (Burmenskaya, Borisova, and Pupyrieva, 2003) have shown, first of all, the significant qualitative differences in selfestimation of children with secure (B) and insecure (A and C) types of attachment. A significant (at statistical level) decrease of self-estimation of children with insecure attachment has been observed by such parameters as popularity and success in communication with peers, competent behaviour - and the most important thing - by the level of general self-acceptance. In other words, children with avoidant and ambivalent attachment were notable for less subjective satisfaction with themselves compared to children with secure attachment. Secondly, self-estimation 
of children with insecure attachment was unstable and fragile and was subject to negative influence to a greater extent. Besides, the third interesting fact came to light: a tendency to inadequate underestimation of their own abilities was typical of children with ambivalent attachment. Meanwhile, in the group of children with avoidant attachment there was inadequately high self-estimation indicating to the action of such means of psychological defence as repression and self-idealization. Further established differences have been unexpectedly confirmed in the work by L.I. Avdeyeva (Avdeyeva, 2005) on the structure of self-concept and self-esteem of children brought up in conditions of the closed child care institution, in a six-year longitudinal observation of formation and dynamics of change in self-attitude. In the context of typology of attachment these children attract particular interest since conditions in which their attachment to a close adult has been formed were sharply impaired. As we know, at present most institutionalized children are orphans whose parents are alive but not able to cope with their parental functions owing to various causes - first of all - by psychological reasons. It means that the majority of such children grow in conditions of insecure and disrupted attachment. What happens then to the development of their self-consciousness, self-concept and self-esteem? How does the breaking of attachment affect them?

It turned out that the self-concept of institutionalized children was essentially lower compared to home-reared kids. It concerns such aspects significant for middle childhood, as achievements in studies, popularity with peers, behavioural competence and even appearance. Besides, their self-concept is less adequate and more labile compared to that of peers living at home. Moreover, another paradoxical feature appeared: a lower level of self-concept of children in orphanage was combined with a relatively high degree of self-acceptance. Analysis of this phenomenon has led to the conclusion that the whole complex of defensive and adaptive mechanisms, such as depreciation, idealization, repression etc, works for supporting these children's subjectively admissible self-acceptance. Owing to intensive work of this complex their self-attitude acquires features of unique attitude, the essence of which is expressed by the formula "Yes, I am a bad pupil and my behaviour is far from good, nobody loves me... but in spite of all this I am good."

However, this "pseudo-positive" self-attitude, created on the surface of consciousness turns out very unstable: the child's low implicit self- esteem appears as a negative notion about his appearance, low claims on "happiness", "down-to-earth" vision of his future, readiness to critical attitude from other people, unsteady self-esteem. Mainly this is a consequence of the major drawback of social situation of development in the child care institution, i.e., children lack attachment and close communication with the adult who is capable of compensating deficiency of stabilizing parental acceptance. In fact, this is nothing else but a remote result of disrupted, deformed and defective attachment.

A more detailed study of the influence of the child's attachment to mother on the formation of his self-consciousness in middle childhood is the subject of research by I.A. Borisova (Borisova, 2007). The author took into consideration the fact that a feeling of one's own significance exists at two levels: conscious and unconscious. Conscious and verbally declared self-concept is considered to be an explicit self-concept while an implicit self-esteem is understood as unconscious one: emotional experience and vague sensations connected with an attitude to oneself exist at less realized levels of psychic reflection and are not subject to correction from the side of consciousness and social standards (a kind of direct, "impulsive" assessment of own ego). In order to measure implicit self-esteem the Implicit Association Test worked out by A. Greenwald has been used. Its procedure was based on measuring intensity and speed of actualization of automatic associations between certain notions of the person (Greenwald, et al., 1995; 1998; 2000; 2002).

With the aid of methods of the Implicit Association Test in addition to explicit (conscious and verbalized) self-concept of most participants of research, characteristics of unconscious, implicit self-esteem have been established. In the sample group of primary school children (80 pupils of the $1^{\text {st }}$ and $3^{\text {rd }}$ forms) $57 \%$ had evident differences in the level of explicit self-concept and implicit (unconscious) self-esteem. One-third of them were characterized by low implicit self-esteem and two-thirds by high one. Self-estimation of some children at the conscious and unconscious levels coincided or were close (concordant structure of selfestimation), other children's self-estimation varied (discordant structure of self-estimation). On the whole the analysis of correlations of explicit and implicit components of self-estimation according to their level has made it possible to identify four types of self-estimation: concordantly high, discordantly overestimated (or protectively high; discordantly un- 
derestimated and concordantly low self-estimation). $43 \%$ of children of the general sample had average values of both types of self-estimation.

Established differences in self-estimation once more showed deficiency and approximate nature of the widely used characteristics of self-estimation, both 'high' and 'low' on the basis of assessment of its explicit (verbalized) components only. We should take into consideration that the essential divergence of outwardly declared self-estimation and internally (unconsciously) felt self-esteem is possible as early as in middle childhood. So, the discordantly overestimated self-estimation $(\mathrm{B} / \mathrm{H})$, contrary to the child's words, cannot be considered positive since it has a defensive character, whereas the discordantly underestimated self-estimation (H/B) sooner points out specific criteria of self-estimation (for example, orientation to modesty and condemnation of pride or deliberately high standard of achievements) than negative self-attitude always perceived as emotional / personality problems.

The research has also shown that one of the powerful factors influencing explicit self-estimation of primary school pupils is their attachment to mother. The strongest attachment to mother affects such aspects of explicit self-estimation as "visual appeal", "general self-acceptance" and (at the level of statistic tendency) "competent behaviour". The level of self-acceptance characteristic of children with secure attachment is essentially higher than general self-estimation of children with ambivalent $(\mathrm{p}=0.024)$ and avoidant $(\mathrm{p}=0.048)$ attachment. However, attachment to mother does not appear as such a significant factor regarding other aspects of concrete self-estimation in middle childhood: children's self-estimation in the sphere of achievements at school, physique (athletic ability) as well as popularity with peers is formed not so much under the influence of mother's attitude, as on the base of assessments of school environment and also on experience of own assessment of objective successfulness in the fields mentioned above. There are more children with high implicit self-esteem and positive self-perception among primary school pupils with secure attachment than among those with insecure types of attachment. More than half of the children with secure attachment have concordantly high self-estimation whereas among children with avoidant attachment this rate is equal to $20 \%$ only, and among children with ambivalent type of attachment it is $12.5 \%$. The most unfavourable picture can be observed in the group of children with anxious ambivalent attachment in which a quarter of children is characterized by concordantly low self-estimation. The so-called "behavioural correlates" of attachment type and self-esteem have been also discovered: for example, in success-failure situations children with secure type of attachment to mother adhere behavioural strategy essentially more often $(\mathrm{p}=0.017)$, while children with ambivalent and avoidant attachment adhere to tactics of "a typical looser". Children with avoidant type of attachment, as a rule, do not join in game emotionally, are not upset when their team is losing and are reserved in showing their joy when winning; it is a neutral reaction that is typical of them. Higher level of anxiety in situation of failure is common for most children with ambivalent attachment. In a winning situation such children give their partners and team the credit for success whereas in a situation of loss they attribute failure to themselves. Such behaviour is indicative of their understated self-esteem and lack of faith in their own abilities. Along with it adequate behaviour is typical of school children with generally high self-esteem.

\section{Attachment and Empathy}

Influence of attachment on formation of emotional / personality sphere of the child has been also studied with regard to such an important feature as empathy (Akimova, 2005). The choice of empathy, i.e., ability to feel compassion, emotional identification with another person, was connected with the fact that conditions of forming empathy have been studied very insufficiently and in a fragmentary way, especially in early and preschool age. It is widely known that young children's individual differences regarding empathy are rather essential. But what does it depend on? As a rule, in studies on development of empathy such factors appear as emotional /personality characteristics of parents, methods and styles of upbringing, communication with peers, as well as the child's general moral development and adoption of ethical norms and values. Meanwhile, it is recognized in theory that empathy arises very early and goes on within mother-child interaction. However, a specific role of attachment type has not been studied and identified yet. We tried to consider the development of the child's empathy in the context of characteristics of his/her attachment. On the one hand, we saw the advantage of attachment system in the fact that psychological education integrates the experience of the child's close interactions beginning 
from infancy in a concentrated way, and on the other hand, it is connected directly with emotional / personality sphere.

The general scheme of development of the child's attachment has turned out to be rather interesting: we faced strongly pronounced differences (percentage wise) of attachment types in various sample groups of children. For example, observing 42 children from two groups of an average kindergarten (age: 5.5-6.5 years old) we could state that only $48 \%$ children had the most favourable, secure type of attachment, whereas children with avoidant attachment amounted to $24 \%$, and those with ambivalent type together with disorganized one made $28 \%$. It should be noted that such ratio of attachment types - when about half a sample (52\%) falls to a share of insecure types - denotes a rather unfavourable contingent of families. In this case one-third of families, which took part in the study, were rated as problem families by one of three following features: low living standard, one-parent family or parental alcoholism. At the same time the research carried out with more favourable contingent of families has shown quite another ratio of types of the child's attachment: secure type (B) - 66\%; insecure types (A and C) - 18\% and $16 \%$, respectively. The range of variation in the individual differences of empathy indices regarding preschool children has turned out to be quite significant. In particular, a group of children with extremely weak indices of empathy made about $20 \%$ (according to results of projective methods of unfinished stories - 17\%), i.e., about one-fifth of them. Statistical analysis has shown secure connection of attachment type with indices of empathy obtained on the basis of both mothers' appraisals and children's reactions and statements in projective situations ( $\mathrm{F}=6.571$ at $\mathrm{p}=0.004)$. It was the secure type of attachment (B) to which corresponded the highest values of indices whereas the weakest displays of empathy were typical of children with avoidant type of attachment (A). The above data concern both the integral index of empathy and the manifestations of empathy directed to mother $(\mathrm{F}=4.307$ at $\mathrm{p}=0.024)$. It should be noted that neither the child's gender, nor its interaction with the attachment factor mattered - a type of attachment has turned out to be the only significant factor.

Thus, on the basis of findings and data derived from literature it is possible to suggest that the most favourable internal preconditions for forming the child's ability to empathize creates a secure type of attachment and the emotional radical inherent in it. As it is known, secure attachment arises in case of mother's sufficient sensitivity and positive mutual relations with her on the whole. Only then the child's strong feeling of security and, along with it, emotional openness, confidence, assertiveness and positive expectations towards people around the child appear. On the contrary, if mother does not have enough sensitivity and responsiveness to her child's states and needs, insecure attachment is being formed, accompanied by the child's doubt in his/her own value and by negative emotions (anxiety, anger - in case of ambivalent attachment - or emotional detachment, reserve and repressed anxiety - in case of avoidant attachment). The corresponding emotional radical (organization of emotional / personality sphere and ways of regulating emotional experience) becomes a co-factor affecting the formation of psychological structures of higher level. As a result, the attachment system appears to be one of the most powerful psychological constructs that help to trace a general path of development in this or that typological variant. The above information is the evidence of significance of the child's early emotional attachments not only in the framework of childhood, but also in the perspective of one's further life. Revealing the weak points and the risks to which the "bearers" of the insecure types of attachment are subject, this data draws our attention to the development of such children and, in fact, puts before practical psychologists a problem of their timely (i.e., as early as possible) detection and correction.

\section{References}

Ainsworth, V., et al. (1978). Patterns of attachment: a psychological study of the strange situation. New York.

Akimova, E.V. (2005). Privyazannost' $k$ materi i razvitie e 'mpatii u detej doshkol'nogo vozrasta [Attachment to mother and development of empathy in preschool children]. Degree work. Moskva: MGU.

Avdeeva, L.I. (2005). Osobennosti samosoznaniya mladshih shkolnikov, vospity'vayushhikhsya $v$ uchrezhdeniyakh zakrytogo tipa [Features of consciousness of the younger schoolboys brought up in orphanage]. PhD thesis. Moskva: MGU.

Avdeeva, N.N., and Haimovskaya, N.A. (2003). Razvitie obraza sebya i privyazannostej $u$ detej ot rozhdeniya do trekh let $v$ seme [Development of self-image and attachment in children from birth till three years in families]. Moskva.

Borisova, I.A. (2007). Osobennosti samoocenki mladshikh shkol'nikov s razny 'mi tipami e'mocional'noj privyazannosti $k$ materi [Features of a self-estimation of children with different types of emotional attachment to mother]. PhD thesis. Moskva: MGU. 
Bowlby, J. (1969). Attachment. London: Penguin Books.

Bowlby, J. (2003). Privyazannost' [Attachment]. Moskva: Gardariki.

Burmenskaya, G.V. (2000). Tipologicheskij podkhod v vozrastnoj psikhologii razvitiya [Typological approach in developmental psychology]. Vestnik Moskovskogo Universiteta. Seriya 14, Psikhologiya, 4. P. 3-19.

Burmenskaya, G.V. (2002). Tipologicheskij analiz ontogeneza individual'ny'kh razlichij [Typological analysis of individual differences in ontogenesis]. Voprosy psikhologii, 2. P. 5-13.

Burmenskaya, G.V. (2003). Problemy' onto- i filogeneza privyazannosti k materi v teorii Dzhona Boulbi [Onto- and phylogenies of attachment to mother in John Bowlby's theory]. In J. Bowlby (ed.). Privyazannost' [Attachment]. Moskva: Gardariki.

Burmenskaya, G.V., Borisova, I.A., and Pupyreva, E.V. (2003). Privyazannost' rebenka k materi i osobennosti ego samoocenki [Attachment of the child to mother and self-estimation]. In Pskikhologicheskie problemy' sovremennoj rossijskoj sem'i. Materialy' Vserossijskoj nauchnoj konferencii [Psychological problems of a modern Russian family. Materials of the All-Russia scientific conference]. Part 1. Moskva.

Cassidy, J. (1988). The self and related to mother-child attachment at age six children. Child Development, 59. P. 121-134.

Fraley, R.C. (2002). Attachment stability from infancy to adulthood: Meta-analysis and dynamic modelling of developmental mechanisms. Personality and Social Psychology Review, 6. P. 123-151.

Fraley, R.C., and Shaver, P.R. (2000). Adult romantic attachment: Theoretical developments, emerging controversies, and unanswered questions. Review of General Psychology, 4. P. 132-154.

Greenwald, A.G., and Banaji, M.R. (1995). Implicit social cognition: Attitudes, self-esteem, and stereotypes. Psychological Review, 102, 1.

Greenwald, A.G., and Farnham, S.D. (2000). Using the implicit association tes to measure self-esteem and self-concept. Journal of personality and social psychology, 79,6 .

Greenwald, A.G., et al. (2002). A unified theory of implicit attitudes, stereotypes, self-esteem, and self-concept. Psychological Review, 109, 1.

Greenwald, A.G., McGhee, D.E., and Schwartz, J.K.L. (1998). Measuring individual differences in implicit cognition: The implicit association test. Journal of Personality and Social Psychology, 74, 6.

Jacobsen, T., Edelstein, W., and Hofmann, V. (1994). A longitudinal study of the relation between representations of attachment in childhood and cognitive functioning in childhood and adolescence. Developmental Psychology, 30. P. 112-124.

Karabanova, O.A. (2004). Psikhologiya semejny 'kh otnoshenij i osnovy' semejnogo konsul'tirovaniya [Psychology of family relations and a basis of family consultation]. Moskva: Gardariki.
Kerns, K., Klepac, L., and Cole, A. (1996). Peer relationships and preadolescents' perceptions of security in the mother-child relationships. Developmental Psychology, 32. P. 457-466.

Kerns, K., et al. (2000). Attachment-based assessments of parent-child relationships in middle childhood. Developmental Psychology, 36. P. 614-626.

Lisina, M.I. (1986). Problemy' ontogeneza obshheniya [Problems of communication in ontogenesis]. Moskva: Pedagogika.

Mikulincer, M., et al. (2002). The affective component of the secure base schema: Affective priming with representations of attachment security. Journey of Personality and Social Psychology, 81. P. 305-321.

Pupyreva, E.V. (2007). E'mocional'naya privyazannost' $k$ materi kak faktor stanovleniya avtonomii lichnosti $v$ mladshem shkolnom vozraste [Emotional attachment to mother as the factor of formation of autonomy in middle childhood]. PhD thesis. Moskva: MGU.

Smirnova, E.O. (1995). Teoriya privyazannosti: koncepciya i e' ksperiment [Theory of attachment: the concept and experiment]. Voprosy 'psikhologii, 3. P. 139-150.

Thompson, R.A. (1999). Early attachment and later development. In J. Cassidy and P.R. Shaver (eds.). Handbook of attachment: theory, research and clinical applications. New York: Guilford.

Thompson, R.A. (2000). The legacy of early attachments. Child Development, 